\title{
Evaluation of distributed multi-agent Energy Management System - cost calculation
}

\author{
Weronika Radziszewska \\ Systems Research Institute \\ Polish Academy of Sciences \\ Warsaw, Poland \\ Email:Weronika. \\ Radziszewska@ibspan.waw.pl
}

\author{
Jörg Verstraete \\ Systems Research Institute \\ Polish Academy of Sciences \\ Warsaw, Poland \\ Email: Jorg. \\ Verstraete@ibspan.waw.pl
}

\author{
Jacek Wasilewski \\ Institute of Electrical \\ Power Engineering, \\ Warsaw University of Technology \\ Warsaw, Poland \\ Email: Jacek. \\ Wasilewski@ee.pw.edu.pl
}

\begin{abstract}
An Energy management system (EMS) is a concept that spans various possible solutions, ranging from basic implementations over solutions that use simple intelligent computer methods to systems that employ advanced intelligent methods. We designed and implemented an intelligent multi-agent based approach that uses a market mechanism to manage power in the microgrid of a simulated Research and Education Center. In this article, the performance of our system regarding cost optimality is compared against two other solutions: the first is a simple solution that uses predefined profiles that define the use of the controllable sources - this provides an upper limit to the cost, the second is the perfect artificial optimum which provides a lower limit to the cost. The perfect optimum resembles a centrally controlled EMS, with the difference that it does not suffer from the delays of detecting power imbalances. The tests show that distributed approach closely resembles the optimal one.
\end{abstract}

\section{INTRODUCTION}

The concept of the microgrid introduces new possibilities regarding more optimal and cheaper use of the renewable power sources and management, not only of supply of power but also of consumption. A microgrid is a small sized grid, equipped with its own power sources, that has a single connection to national power grid. In addition, it can be (temporarily) disconnected from the national power grid. The microgrid allows for more internal balancing of power, which increases safety of power supply, better use of power from renewable sources and allows for reducing peaks in the national power grids. There are many features that discern microgrids from big power systems. The issue has been discussed in detail in [1]. Essential features for functioning microgrids as semiautonomous power systems include the use of power electronic converters and the use of specific control systems. It also needs the ability to communicate within the microgrid.

Energy management systems (EMS) are systems to control the energy in some area, the energy can be electrical, heat or even cooling systems - only electrical energy is considered in this article. An EMS can be a simple implementation, but it can also employ more advanced computer methods, even involving advanced intelligent methods. The EMSs are the key to smart grids and to microgrids' efficiency. There are many EMS solutions for smart grids, from centralized solutions [2], via hierarchical ones [3] to distributed ones [4]. In this article an evaluation of a distributed multi-agent module of EMS Short-time Balancing System is discussed.

The Short-time Balancing System was created to manage a very specific microgrid: our test case of a Research and Education Center (REC). The detailed description of REC is presented in next section. The requirements of EMS were to be a fully distributed, agent-based system, whose balancing mechanism includes the a auction mechanism. The general description of the system will be presented in section III.

The algorithms and methods used to optimize the speed of power balancing by the Short-time Balancing System were presented in [5] and [6]. To evaluate the algorithm of balancing it should be compared to a benchmark solution. The fact that the system and REC are simulated, allows for different experiments and configurations. The performance of our system with respect to cost optimality is compared against two other solutions: the first is a simple solution that uses predefined profiles that define the use of the controllable sources - this provides an upper limit to the cost (this solution is described in section VI), the second is the perfect artificial optimum which provides a lower limit to the cost (described in section V). The perfect optimum resembles a centrally controlled EMS, with the difference that it does not suffer from the delays of detecting power imbalances; a true centralized system will have a cost slightly above the optimum, as any system needs time to detect imbalances when they occur and also needs time to adjust to them.

The comparison value is the cost in PLN of a day of operation of the microgrid. The costs are presented in section VII. The last section concludes the article.

\section{RESEARCH CENTER MICROGRID}

The aim of the REC is to research new renewable energy and smart grid technologies, as well as spread the knowledge about more environmental behaviors, by organizing conferences, courses and seminars. It is assumed that the center will host a research institute, a conference center and a hotel. The microgrid is a low voltage network (LV, $0.4 \mathrm{kV})$, connected to a medium voltage supply line (MV, $15 \mathrm{kV})$ via an MV/LV (15/0.4 kV) transformer substation [7]. The REC is equipped with the following renewable power sources: 2 sets 
of photovoltaic panels and 3 wind turbines; it also contains two controllable micro power sources: a gas microturbine and a gas-fueled reciprocating engine. Additionally, the microgrid is equipped with two types of power storage units: a set of accumulator batteries and a set of flywheels.

The microgrid consists of 128 nodes, where a node is a point of the network to which the devices with a similar purpose are connected, it is the smallest unit that is measured and controlled. The number of devices that are connected to a single node varies: some nodes can gather a large number of small devices (e.g. lights in the conference room), others have a single device connected (specially used to provide better insight in specific devices, e.g. gas microturbine). A more detailed description of the microgrid can be found in [5].

The microgrid is equipped with controllable devices. For these, the EMS can request to adjust the produced or consumed power accordingly, within the technical limitation of the device. Such devices are non-renewable power sources (reciprocating engines, gas microturbines), as well as batteries. Wind turbines and photovoltaic panels are considered uncontrollable devices, as the amount of their production depends on the weather conditions and cannot be changed by the EMS. Bigger wind turbines are controllable, but the smaller models used in the microgrid lack this functionality.

\section{EMS AND BALANCING ALGORITHM}

The EMS developed for this microgrid was made with the idea of a complex approach to energy management. The full EMS includes various modules: from demand side management by scheduling events that consume significant amounts of power to calculating the reliability indices for continuity of power supply. The details of the system are presented in [8]. One of the components of the EMS is a Short-time Power Balancing system, which is responsible for changing the operating point of controllable devices in the microgrid. Such control is directly influencing the cost of operation of the REC. The Short-time Balancing system is a distributed and multi-agent system, it is not dependent on a central control point and allows for distributed calculation, which increases the reliability of the solution. The multi-agent paradigm was considered to be very useful in this situation: agents can be given the necessary intelligence to make a decision, and communication between agents is one of the main aspects in a multi-agent system. It also introduces a parallel operation, which on one hand increases the speed of balancing, but on the other hand can cause the unwanted behavior and race conditions. A more detailed description of this system is presented in [6]. The Short-time Balancing system's aim is to optimize the operation of the microgrid.

The choice of which controllable source to use is made by means of relative cost, which not necessarily has to reflect the real cost. If it reflects the real cost the cheapest sources will be preferred, other cost assignments can result in a power balancing scheme that behaves differently. The most intuitive purpose is to minimize the cost of operation, but other purposes can be considered. Maximizing the use of clean power sources could be a second criterion. A third purpose can be shaving the peaks of power usage: in power networks, peaks of power usage pose a problem, as the grid has to be able to cope with those peaks. Microgrids, with their own sources and storage, can help in shaving the peaks. The criteria for optimization considered here is a combination of cost minimization, environmental optimization and optimal usage of the resources present in the microgrid.

Considering the aim of REC and the reasons it was designed, it is assumed that the exchange of power between the external power grid and the microgrid should be minimized. It is not always the case that the power from external (national) power grid is more expensive or more polluting (the ecological aspects are also considered), but considering that the prices of power in external power grid tend to grow and that the microgrid has an ability to work in island mode (disconnected from external power grid and balancing the demand and supply at every moment), the scenario of limiting the exchange of power seems very desired. In this case we assume that selling power to the external power grid brings minimal or no income and buying power from the external power grid is more expensive than producing it internally. The Short-time Balancing System is made in a way that the relative prices (and the same order of the preferred producers) can be easily changed and the system will adjust itself to different model of balancing.

The Short-time Balancing System does not manage the operating point of power consuming devices. The demand side management in the system is realized by the Planner, a module that schedules tasks that require large amounts of energy, like experiments, demonstrations or events, like conferences or lessons. The Planner is not directly managing the operating point of devices, it rather urges the people working in REC to performance certain activities when it is more convenient for the EMS. As such, its presence or absence makes no difference to these experiments.

The devices present in the microgrid are grouped by nodes; for the Short-time Balancing System, a node will be the smallest participant. The balancing mechanism is initiated by either a node containing energy consumer or a node containing an uncontrollable source, whose operating point changes: a light gets switched on or off, or the output of a photovoltaic panel increases or decreases. When the operating point of a consumer increases, the effect on the system is the same as if the operating point of an uncontrollable source decreases: there will be a deficit of power (a negative imbalance), and additional power needs to be supplied. The reverse happens when the operating point of a consumer decreases or that of an uncontrollable source increases. At this point, the node that causes the imbalances signals to all other devices that an imbalance occurs and requests offers from devices to solve this imbalance. The only devices that are a possibly capable of dealing with the imbalance are the controllable sources, they answer the request for offers: for a negative imbalance each controllable source provides the amount of power it can supply and the cost, for a positive imbalance this will be the amount of 


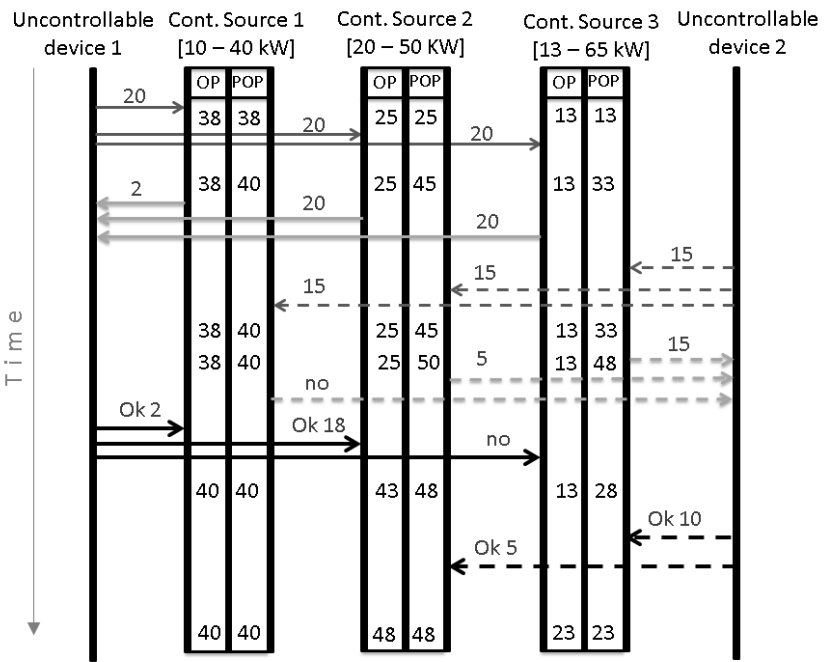

Fig. 1. An example of the balancing mechanism where the not-optimal distribution of power occurs.

power they can decrease and the profit. From this list of offers, the node that caused the imbalance chooses the option with the lowest cost or highest profit, potentially selecting multiple devices to cover the imbalance.

That way of choosing is a realization of a greedy algorithm for power production optimization, which should give the optimal solution when immediate communication between the agents is considered. However, in real experiments, when there are multiple devices that cause imbalances and multiple devices that can cover it, a sub-optimal behavior is observed. It is connected to the asynchronous operation of the multiagent system and the delays in message sending between the agents. Consider the example in fig. 1: there are two consumers and three controllable sources. Their operating points are specified in the respective columns OP. At one point in time, an uncontrollable device 1 requests for an additional $20 \mathrm{~kW}$. This can be covered by the two cheapest controllable sources. They report how much they can cover $(2 \mathrm{~kW}$ and $20 \mathrm{~kW}$ respectively), and increase their provisional operating point (POP) - this is the operating point that they would have if the offer is accepted. Before the uncontrollable device accepts the offer, a second uncontrollable device causes an imbalance of $15 \mathrm{~kW}$. As the provisional operating point of the cheapest controllable source is at maximum, it cannot send an offer. The second controllable source sends an offer for $5 \mathrm{~kW}$, the third controllable source sends an offer for $15 \mathrm{~kW}$. When the first uncontrollable device accepts the offers it got, this alters both the operating points and provisional operating points of the first two sources, this however does not change the offers that were sent to the second uncontrollable device. It accepts the offers it got, employing the more expensive source while leaving the second source still with a reserve of $2 \mathrm{~kW}$. This is not the optimal situation; it can only occurs $=$ when there are three or more controllable sources with different prices. In this case, it only occurs when a controllable device is near its maximum or minimum and an imbalance cannot be solved by one of the controllable sources alone. In reality, unlike in the example, the imbalances are of much smaller magnitudes so the non-optimality occurs at a smaller scale. Furthermore, future imbalances will again prefer to cheaper source, which also causes this sub-optimal situation to be quickly resolved, so this behavior is limited in time.

The standard behavior of the Short-time Balancing System is optimizing for the operation cost of the microgrid. While the Short-time Balancing System is capable of adjusting operating points quite optimally, it cannot decide on whether or not a controllable source needs to be powered on or can be powered off. This is due to the fact that the Short-time Balancing System does not consider predictions, but merely considers the current situation and reacts to immediate changes. The Planner, which should contain information on activities of energy consumers and prediction of the operating point of the uncontrollable sources, is capable of making such decision. This makes the Planner the first stage in the optimization process. However, the Short-time Balancing is a critical component in this process, and its operation can be verified and tested without the Planner.

The example of balancing behavior of Short-time Balancing System is presented in Fig. 2. In the setup, there were 5 consumers (aggregated to one for clarity of the figure), gas microturbine, engine, external power grid and two wind turbines. The time between recognition of imbalance to confirming the balancing action was by average $56 \mathrm{~ms}$. It can be seen that the system is not using the external power grid unless there is really no other choice: when the operating point of a controllable source is near its upper or lower limit, the source has no more control capabilities in one direction. When this happens for all controllable sources, they no longer can maintain stable power in the microgrid without the help of the external network. The system is also reducing the operating point of the more expensive source, in this case the gas microturbine. The overall sum of production and consumption has to be maintained the same and the Short-time Balancing System is managing to achieve that.

\section{Calculating cost of Operation}

The cost of installation of renewable power sources, batteries and measuring system (smart metering) is still quite high, even though the popularity of such devices is growing. From an investor point of view, the decision of building such facilities has to be carefully calculated taking into account the future prices for electric energy, maintenance costs and the other factors. In this work, we are free from such dilemmas, as the REC is made to research the new technologies for power production and the reason for its installation is well defined and does not have to consider the return of investment time. That is also a reason why we would not consider amortization costs of operation of the research center, as it is included in the cost of fulfilling the goal of the building which is spreading and widening the knowledge about these technologies. 


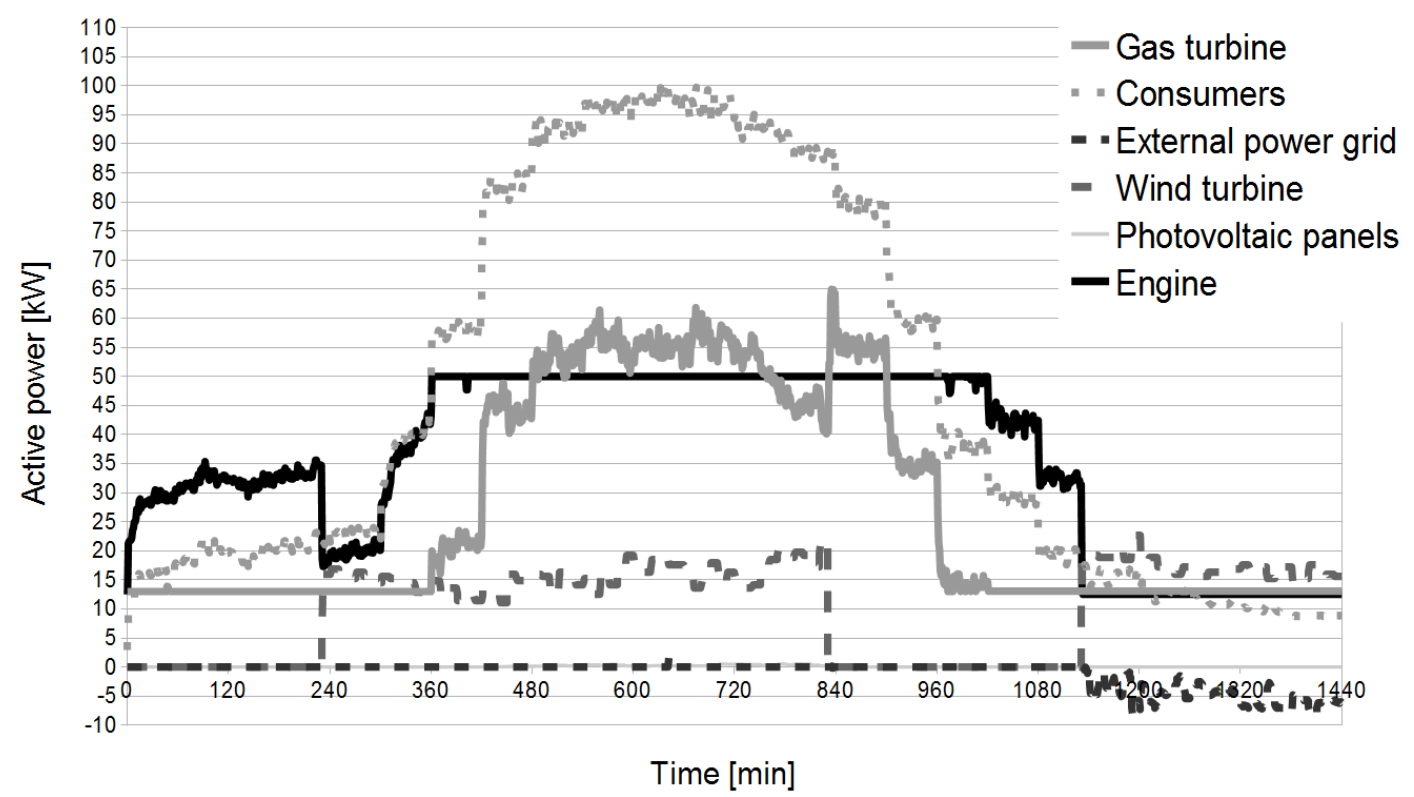

Fig. 2. The example operation of Short-time Balancing System.

The costs that are considered, are the cost of the current operation of the considered devices, under such conditions, the renewable power sources produce almost free energy. On the other hand the controllable power sources like gas microturbine and reciprocating engine need fuel to their operation and the cost of this should be considered.

In next paragraphs, the short description of the models of devices that were used in the system will be presented.

a) Gas microturbine: The gas microturbine modeled in this system has a nominal power of $65 \mathrm{~kW}$ with the allowed operating point between $20 \%$ and $100 \%$ of its nominal power [9]. This unit works as a cogeneration device (produces heat and electric power). The cost of producing electric energy by this device $K^{G M}(t)$ [PLN] can be defined by equation:

$$
K^{G M}(t)=B^{G M}(t) W_{p} k_{j p}
$$

Where: $B^{G M}(t)$ - usage of gas/biogas $\left[\mathrm{m}^{3} / h\right], W_{p}$ - average calorific value $\left[\mathrm{kWh} / \mathrm{m}^{3}\right]$ estimated at $6.0 \mathrm{kWh} / \mathrm{m}^{3}, k_{j p}$-cost of fuel unit [PLN/kWh] assumed to be $0.2 \mathrm{PLN} / \mathrm{kWh}$.

The usage of gas can be calculated from the following equation:

$$
B^{G M}(t)=\frac{P_{e}^{G M}(t)}{\eta_{e}^{G M}\left(\frac{P_{e}^{G M}(t)}{P_{N}^{G M}}\right) W_{p}}
$$

where: $P_{e}^{G M}(t)$ - average electric power produced by gas microturbine during time $t[\mathrm{~kW}], \eta_{e}^{G M}$ - electrical efficiency of gas microturbine [-], $P_{N}^{G M}-$ nominal power of the source $[\mathrm{kW}]$.

The efficiency of gas microturbine depends on the operation point of the turbine and is described by the following equation:

$$
\begin{aligned}
\eta_{e}^{G M}\left(\frac{P_{e}^{G M}(t)}{P_{N}^{G M}}\right)=- & 0.196\left(\frac{P_{e}^{G M}(t)}{P_{N}^{G M}}\right)^{2}+ \\
& 0,419\left(\frac{P_{e}^{G M}(t)}{P_{N}^{G M}}\right)+0.0387
\end{aligned}
$$

The change of efficiency depending on the operating point is presented in Fig. 3.

b) Reciprocating engine: The reciprocating engine is also powered by gas or biogas, its maximum power is $50 \mathrm{~kW}$ and it is also a cogeneration unit [9]. The cost of operation (without amortization costs) is expressed by the following equation:

$$
K^{E}(t)=B^{E}(t) W_{p} k_{j p}
$$

Where: $B^{E}(t)$ - usage of gas/biogas $\left[m^{3} / h\right], W_{p^{-}}$average calorific value $\left[k W h / m^{3}\right]$ estimated at $6.0 \mathrm{kWh} / \mathrm{m}^{3}, k_{j p}$-cost of fuel unit [PLN/kWh] assumed to be $0.2 \mathrm{PLN} / \mathrm{kWh}$.

The usage of gas can be calculated, similarly to the gas microturbine, from the following equation:

$$
B^{E}(t)=\frac{P_{e}^{E}(t)}{\eta_{e}^{E}\left(\frac{P_{e}^{E}(t)}{P_{N}^{E}}\right) W_{p}}
$$

where: $P_{e}^{E}(t)$ - average electric power produced by engine during time $t[\mathrm{~kW}], \eta_{e}^{E}-$ electrical efficiency of engine [-], $P_{N}^{E}$ - nominal power of the source $[\mathrm{kW}]$.

The electrical efficiency was estimated and is given by equation: 


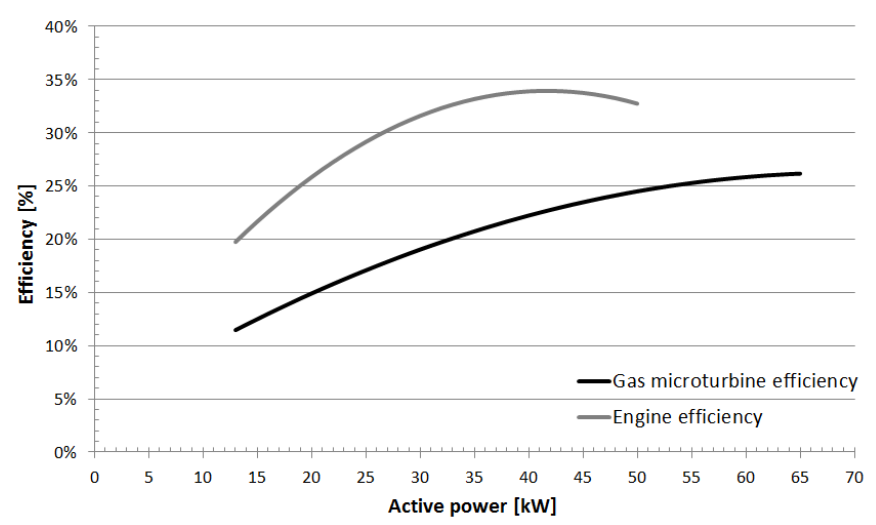

Fig. 3. The efficiency of producing power by the gas microturbine and reciprocating engine.

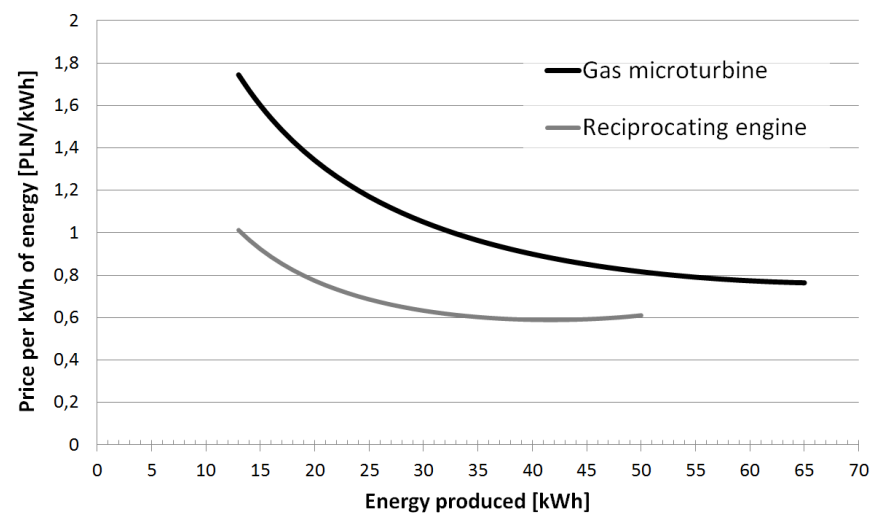

Fig. 4. The cost of producing fuel by the devices.

$$
\begin{aligned}
\eta_{e}^{E}\left(\frac{P_{e}^{E}(t)}{P_{N}^{E}}\right)=-0.432\left(\frac{P_{e}^{E}(t)}{P_{N}^{E}}\right)^{2}+ \\
0,72\left(\frac{P_{e}^{E}(t)}{P_{N}^{E}}\right)+0.0395
\end{aligned}
$$

The diagram of electrical efficiency is also presented in Fig. 3. As can be seen the Engine has higher efficiency factor, so as a source for electrical energy it is more fuel efficient and therefor cheaper. However, when the cogeneration aspects are considered the gas microturbine might be more efficient.

The price of the controllable power sources dependent on the operating level are presented in Fig. 4.

c) External power grid: The current average price of power in the external power grid in Poland is fairly low [10]. The average cost per $\mathrm{kWh}$ is around 0.3 to 0.4 PLN, plus around the same value for the distribution of power and some additional fees. Comparing that to the price for energy produced by controllable sources, see Fig. 4, shows that the price of electricity from micrgrids own sources is higher. But it is not fully the case. Both gas microturbine and engine are cogeneration units which, in case of no connection to systematic heating system, are the most efficient heat sources.
In cogeneration the efficiency of burning fuel is high and the cost of not using electricity for heating should be subtracted from the cost of producing electricity. What is more, in case of microgrids their own power sources have no additional fees for distribution of power or the maintenance of connection. Also, the internal production of energy is necessary in island mode operation. The combination of renewable and fuel-based controllable power sources allows to maintain fairly stable microgrid in case of blackout in the external power grid. Due to the fact that the renewable power sources are almost cost-free, the combination of renewable power source and gas microturbine gives the overall average prices that are much lower than any tariffs with the national power grids.

The assumption of the system was to keep the exchange of power between external power grid and microgrid minimal, but we did not have data to include full cost calculation on microgid side, that is why the prices of power from external power grid had to be set artificially. The cost of power from external power grid is set to $0.9 \mathrm{PLN} / \mathrm{kWh}$ for the energy taken from the grid (including distribution fee) whereas sending energy to the grid brings $0.05 \mathrm{PLN} / \mathrm{kWh}$ of profit.

d) Battery: The model of the microgrid includes battery and flywheel as a power storage units. The flywheel is a device that only works as a buffer of energy due to its inability to store the energy for long time. That is why it is not considered as a storage unit that can be managed by the system. The battery is a device that requires control at any point of its operation, in the simplest situation it needs the information whether it shall be in charging or discharging mode. The battery can be treated in EMS in two ways: or it is a device that takes part in the balancing, changing its operating point (setting charging or discharging mode) to supply power or consume power; or it is treated as intermediary device that is only a buffer between the producers and consumers.

The cost comparisons were done without the presence of a battery in either the agent based EMS or the optimal operating points calculator. The reason for this, is that there needs to be some prediction of the future power consumption and production so that the management system can decide whether or not it is a good time to charge the battery. This decision is impossible to make from just looking at the current power supply and demand situation. When the system has knowledge about the future energy supply and usage, ideally, the battery should be charged when there will be a surplus of energy to prepare it for discharging when there will be a deficit of power. Such knowledge can only come from a predictor that has a prior information about typical profiles. If the same predictor were to be used in either the agent based EMS or in the optimal operating points calculation, the battery will behave either as a normal consumer that consumes when there is a surplus of power (when the situation is good for charging it), or as the cheapest supplier when there is a shortage of power. In the end, this would not influence the cost calculation differently from adding a consumer or producer, but it would complicate the calculations and the visualization.

A battery is very useful in situation of variable prices in 
external power grid, especially when the prices follow some averaged profile (e.g. represented by multiple tariffs, peak/offpeak prices). The storage device can include in its profiles and predictions the prices of power from external power grid and set its state (charging/discharging) to use the most of cheaper energy.

\section{THE CALCULATION OF OPTIMAL OPERATING POINTS}

The first benchmark for multi-agent Short-time Balancing System is the system that simulates the optimal operating points for all controllable devices in the microgrid. We assume that it has information about the demand and supply of power in every moment in time. As such, it has enough knowledge to decide to switch on or off controllable power sources, which in some cases would be justifiable. This possibility was blocked to make it possible to compare the costs of operation with the operating points calculated by Short-time Balancing System. In the considered EMS the decision about switching on or off the controllable source is made by different module - the Planner that uses prediction of electricity and heating requirements to decide when and which devices should be active. The tests considered only Short-time Balancing System, and experiments were run without the Planner, thus without the possibility for switching off controllable sources. The reason for that is the same reason as why the experiments were run without the battery: both optimal and multi-agent system need to use the same predictor, which would only add more data without having an influence on the end result.

The algorithm for calculating the optimal operating points requires list of all active nodes and power sources, forecast of weather conditions and prediction of usage in each node. First, the program calculates the sum of consumption in given period, counting all active nodes. Then, it calculates the sum of production of power from renewable power sources in given period (sum from all photovoltaic panels and wind turbines). The remaining power is production and consumption that cannot be controlled; the difference between them is what really has to be balanced. With this knowledge, it is possible to calculate the operating point of controllable producers in a way to cover all imbalances. The idea is to first use to the maximum operating point the cheaper sources (excluding the power from external power grid) and then use the more costly. The remaining imbalances are assigned to the external power grid. Having all that data allows to calculate cost of production from controllable power sources, according to the equations presented in section IV. The cost of power from external power grid is calculated using fixed price per $\mathrm{kWh}$ and from it is subtracted the income from selling energy to the external power grid.

In Fig. 5 the example solution of the EMS system is presented. As can be seen, the system uses the cheapest energy first and uses the energy from external power when there is no other choice.

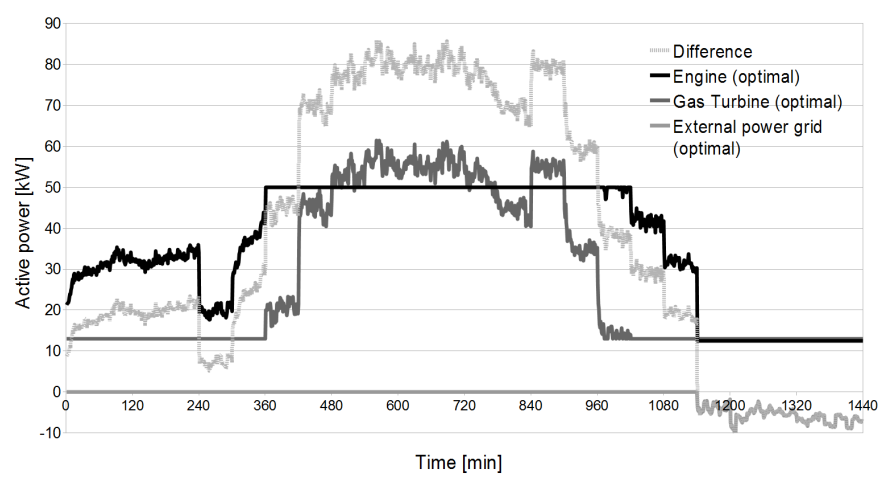

Fig. 5. The example of the operating point choice by the optimal algorithm with full knowledge.

\section{MANAGing With PREDEFINED PROFILES}

The optimal operating point calculation has the advantage of knowing exactly the state of the microgrid in every moment in time. That is a perfect, but not possible situation. In practice the historical knowledge is used by defining the profiles of power usage and the profiles of weather conditions. It allows to set the operating points of controllable devices ahead, hoping that the prediction is good.

The consumption nodes are by default not controllable, in the system the power usage is a subject to planning, but it is an action that is executed by the people interacting with the system, not enforced by automatic control. The controllable power sources have to have some level of production set. We assume that there is some prior knowledge about the level of power usage in the microgrid, e.g. from past measurements. That allows to estimate the power needed to be produced to keep the power more or less in balance. The real balancing device will be the external power network that can provide or consume infinite amounts of power (actually it would be the amount limited by the connection that the microgrid has to the distribution network, but we make here a simplification). The renewable power sources operate with a goal to produce as much power as possible in the given conditions.

The calculator of cost for such scenario was developed, it is very similar to the algorithm of optimal operating points calculator, the main difference is calculation of operating point of controllable producers. In the calculation the same assumption as before is made that exchange of power between external power grid and microgrid should be minimized. The control assumes that the data about consumption and production from renewable power sources are given by the profile that has one averaged value per hour. The choice of the time interval is arbitrary, but it is a common time interval for profiles. That means that the operating points of controllable devices will be set once per hour. All the imbalances that appear are dealt with by external power grid.

The profiles are created by averaging the real consumption and renewable production levels, divide this into one-hour intervals and then setting the operating points for the controllable sources to this average for one hour. In the presented 


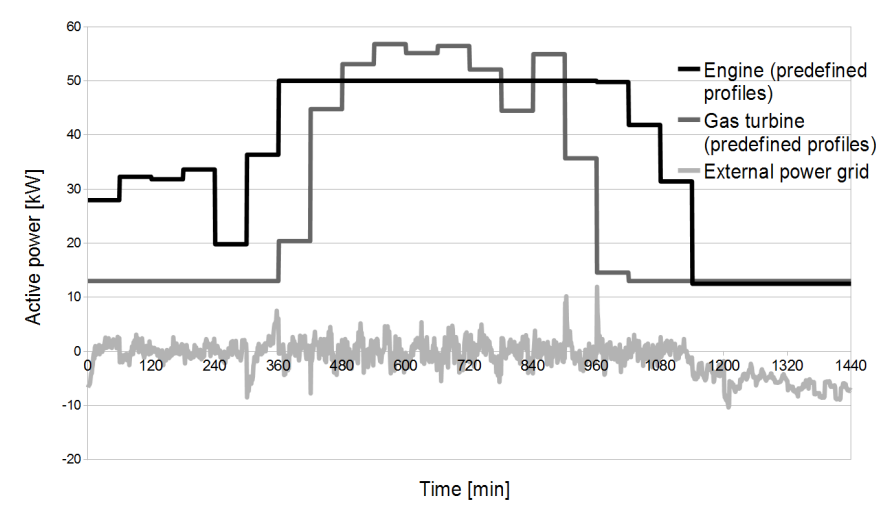

Fig. 6. The example of the operating point choice by using predefined profiles.

experiments, the averages of the simulated day are used; this makes the error of the profile relatively small. In a more realistic scenario, the averages would have been calculated using data from a longer period, yielding a profile that will exhibit a bigger error compared to the optimal. Because of the choice of the average profile over the same day, the amount of power produced by controllable sources during the entire day will match the amount of the optimal profile. Despite this, the averaging profile will perform worse, as it does not necessarily choose optimal sources or optimal operating points. The profile is therefore the best possible averaged profile for this day, which still provides an upper limit to the total cost.

In Fig. 6 the example solution of the microgrid management with predefined profiles is presented. As can be seen the system uses the power from external power grid more extensively, simply to maintain the balance.

\section{COST COMPARISON}

The presented solutions have the same aim and work on the same data of weather conditions and face the same consumption profile. The solutions were compared and overlaid on a graph in Fig. 7. In the figure, only the controllable power sources are shown, as this is the only aspect where there can be a difference. The pairs of devices (engine and gas microturbine) from each solution are represented with the same color, but with different style of line. The solutions clearly follow the same pattern, which means all solution set the operating points not too differently from the optimal profile. The profiles for the controllable sources in the solution with predefined profiles deviates the most, as it uses the external network for balancing rather than the available controllable sources. The Short-time Balancing System has operating points that very close resemble the profiles of the optimal solution. It has some small delays in changing the operating point, but that is due to the fact that it is the only EMS that was simulated in real time: some time is needed to detect an imbalance. Different simulations show the same and expected behavior, as was described earlier.

At 240 minutes, it seems Short-time Balancing System changes the operating point earlier than the other solutions.
TABLE I

COMPARISON OF COSTS USING SHORT-TIME BALANCING SYSTEM, OPTIMAL CALCULATION OF OPERATING POINTS AND THE EMS WITH PREDEFINED PROFILES.

\begin{tabular}{|l|l|l|l|}
\hline & $\begin{array}{l}\text { Short-time Bal- } \\
\text { ancing EMS }\end{array}$ & $\begin{array}{l}\text { Optimal } \\
\text { solution }\end{array}$ & $\begin{array}{l}\text { EMS with } \\
\text { predefined } \\
\text { profiles }\end{array}$ \\
\hline cost of gas & 1276.79 & 1276.54 & 1276.295 \\
\hline $\begin{array}{l}\text { cost of power } \\
\text { from external } \\
\text { power grid }\end{array}$ & -2.369 & -2.838 & 6.670 \\
\hline total cost & 1274.421 & 1273.703 & 1282.959 \\
\hline
\end{tabular}

This is a side effect of aggregating the data in time: the devices set or report their operating point once per minute, but this interval is not synchronized between devices. Aggregating the data to match the time scale of the other solutions, to be able to show it on a graph, can yield the side-effect as it appears at the 240 minute mark.

The cost of operation was calculated, using the equations presented in section IV. The result of cost comparison is presented in table I. It can be seen the Short-time Balancing System does not differ much from the optimal solution. The cost of fuel (in this case gas) is very similar in all three approaches, because, as can be seen in Fig. 7, the total fuel needed for all controllable sources during the day are very similar. The operating point of system with predefined profiles is an average of the optimal profile, so its gas usage is very similar. Because EMS with predefined profiles uses the external power grid to balance its cost of using it is visibly higher.

The Short-time Balancing System is suffering from delays in first detecting the change and then reacting to it. These delays always occur, both with increase and decrease of power, consequently over long time they partially even out, drawing the cost closer to the cost of optimal solution.

The actual cost of operation of the microgrid depends on many factors, the prices of gas and power from external power grid are fixed, which in realistic conditions could be changing or simply different. The important here is that the distributed system, which thanks to its agent architecture is more robust to failures, can set operating points to almost optimal values.

\section{CONCLUSION}

The Short-time Balancing System is a distributed EMS that is successfully managing to balance the power in the microgrid within required time (the average is below $60 \mathrm{~ms}$ for average balancing time, on an accelerated simulation using a single computer). The way it is adjusting the operating points of controllable devices is following the pattern of the optimal solution. The cost comparison without real system is difficult to define as some simplifications have to be done, e.g. not allowing the systems to switch off the power sources when they are not needed. The presented comparison here was aimed at comparing the performance of the system with the optimal setting of operating points and with a system that only knows the predefined profiles of consumption and renewable source 


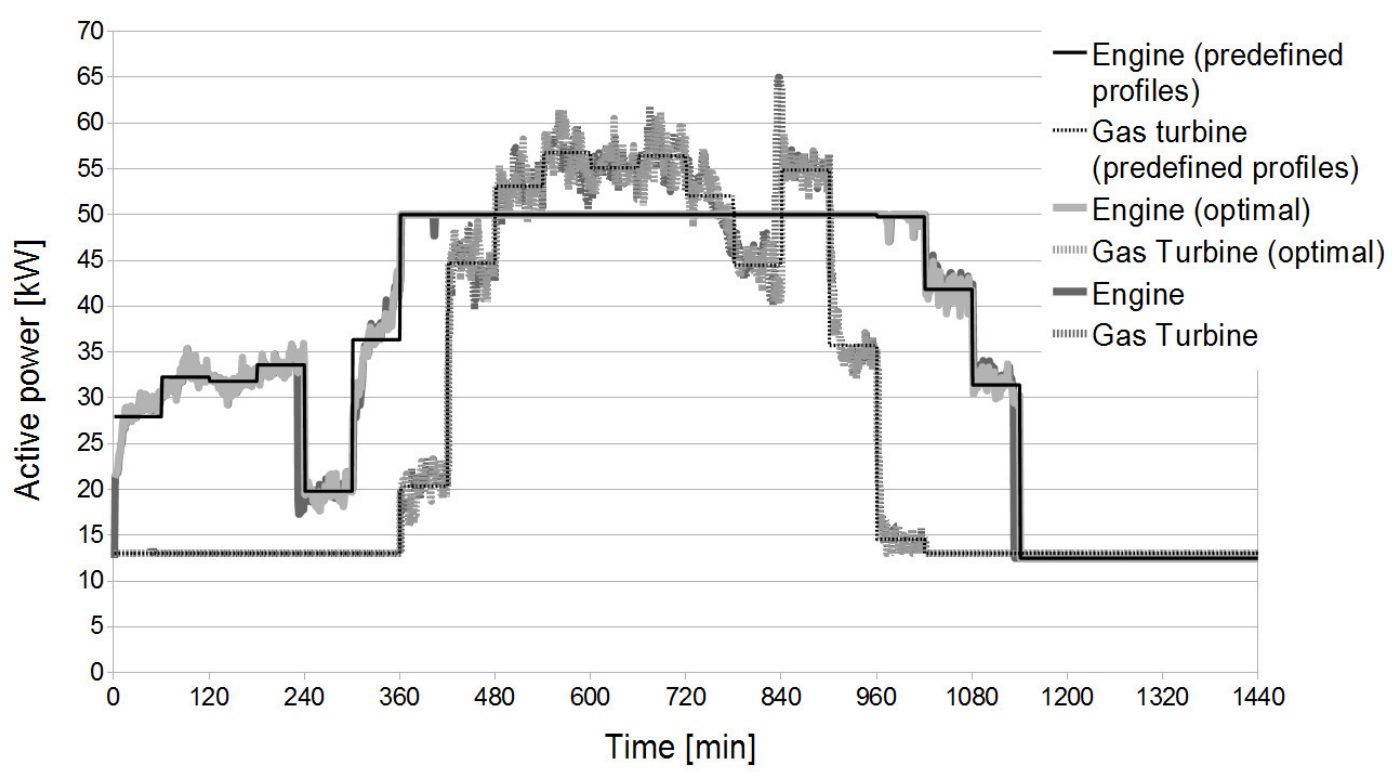

Fig. 7. The comparison of operation of controllable power sources and external power grid using different solutions.

production. The most basic comparison involves the operating points, which directly define the cost of fuel usage, which consequently is a good comparison factor. To fully evaluate real costs of operation, the cogeneration units have to evaluated considering the cost and usage of heating at the moment of tests, for example cost of microturbine and engine should be corrected by the factor of not used amount of power for heating the buildings in REC.

The way the microgrid uses its own production sources depends on the choice of the aims of the EMS system. In the example used in this article, external network and local controllable sources were used, and conclusions from this data were drawn. This is merely to illustrate the capabilities of the Short-time Balancing system. Under the assumptions made, if the main goal is to operate microgrid as cheaply as possible there will be a much larger usage of power from the external power grid than in situation where the independence from the national power grid is rewarded. Different settings in the cost functions of different devices allow for changing the behavior of the balancing strategy, additional sources will be selected according to their cost profiles.

Comparison shows that the Short-time Balancing System is working almost optimally. It is reflected by the cost of operation which is also very similar.

\section{ACKNOWLEDGMENT}

The research of W. Radziszewska was supported by the Foundation for Polish Science under International PhD Projects in Intelligent Computing. Project financed from The European Union within the Innovative Economy Operational Programme 2007-2013 and European Regional Development Fund.

\section{REFERENCES}

[1] R. Lasseter, A. Akhil, C. Marnay, J. Stephens, J. Dagle, R. Guttromson, A. S. Meliopoulous, R. Yinger, and J. Eto, "White paper on integration of distributed energy resources: The certs microgrid concept," CERTS, Tech. Rep., April 2002.

[2] A. Tsikalakis and N. Hatziargyriou, "Centralized control for optimizing microgrids operation," Energy Conversion, IEEE Transactions on, vol. 23, no. 1, pp. 241-248, March 2008.

[3] M. D. Ilic and S. Liu, Hierarchical power systems control its value in a changing industry, ser. Advances in industrial control. London, Berlin, Paris: Springer, 1996. [Online]. Available: http://opac.inria.fr/record=b1104385

[4] M. Vasirani and S. Ossowski, "A collaborative model for participatory load management in the smart grid," in Proc. 1st Intnl. Conf. on Agreement Technologies. CEUR, 2012, pp. 57-70.

[5] W. Radziszewska, Z. Nahorski, M. Parol, and P. Pałka, "Intelligent computations in an agent-based prosumer-type electric microgrid control system," in Issues and Challenges of Intelligent Systems and Computational Intelligence, ser. Studies in Computational Intelligence, L. T. Kóczy, C. R. Pozna, and J. Kacprzyk, Eds. Springer International Publishing, 2014, vol. 530, pp. 293-312. [Online]. Available: http://dx.doi.org/10.1007/978-3-319-03206-1_20

[6] P. Pałka, W. Radziszewska, and Z. Nahorski, "Balancing electric power in a microgrid via programmable agents auctions," Control and Cybernetics, vol. 4, no. 41, pp. 777-797, 2012.

[7] J. Wasilewski, M. Parol, T. Wojtowicz, and Z. Nahorski, "A microgrid structure supplying a research and education centre - Polish case," in Innovative Smart Grid Technologies (ISGT Europe), 2012 3rd IEEE PES International Conference and Exhibition on, 2012, pp. 1-8.

[8] W. Radziszewska and Z. Nahorski, "A multiagent energy management system for a small microgrid equipped with power sources and energy storage units," in International Congress on Energy Efficiency and Energy Related Materials (ENEFM2013), ser. Springer Proceedings in Physics, A. Y. Oral, Z. B. Bahsi, and M. Ozer, Eds. Springer International Publishing, 2014, vol. 155, pp. 411-417. [Online]. Available: http://dx.doi.org/10.1007/978-3-319-05521-3_53

[9] D. Kowalska, M. Parol, J. Wasilewski, and T. Wójtowicz, "Opracowanie uproszczonego (przez przyjęcie zintegrowanych modeli urządzeń i instalacji cieplnych) projektu sieci (fragmentów instalacji) cieplnej w poszczególnych obiektach ośrodka badawczo-szkoleniowego, łạcznie z określeniem odbiorów ciepła oraz doborem rozproszonych źródeł ciepła (kolektorów słonecznych, kotłów do spalania biomasy), a także zasobników ciepła (urzạdzeń grzewczych, urzạdzeń chłodniczych)," Systems Research Institute PAS, Tech. Rep., 2010.

[10] ARE s.a, "Energia.pl," http://www.energia.pl/porownanie_obrot.php. 